\title{
0634 OCCUPATIONAL VIOLENCE IN THE SCHOOLS: A CASE-CONTROL STUDY OF PHYSICAL ASSAULT AGAINST EDUCATORS
}

S G Gerberich*, N M Nachreiner, A D Ryan, T R Church, S J Mongin, P M McGovern, M S Geisser, G D Watt, D M Feda, S K Sage, E Pinder Correspondence: Division of Environmental Health Sciences, Regional Injury Prevention Research Center and Center for Violence Prevention and Control, , School of Public Health, University of Minnesota, , 420 Delaware Street SE, MMC-807, Minneapolis, MN 55455, USA

\subsection{6/ip.2010.029215.634}

Prior research has primarily focused on student-on-student school violence; yet, school educators are also at risk nationally and internationally. A two-phase study was designed to identify risk factors for assaults against educators (kindergarten-grade 12). Educators ( $\mathrm{n}=26000)$ were randomly selected from the Minnesota license database and screened for eligibility (6180, eligible) by mailed questionnaire. Phase I (12-month recall) identified eligible cases $(n=290)$ and controls $(n=867)$ and violent event characteristics; Phase II (case-control 1-month recall prior to assault and randomly selected month, respectively) enabled identification of numerous exposures. Confounders were selected for multiple logistic regression analyses using directed acyclic graphs; reweighting adjusted for response and eligibility biases. For each study phase, response was $84 \%$. Assault perpetrators were primarily students (95\%). Risks (ORs; 95\% CIs) increased for educators working in: special education (3.66, 2.46 to 5.44) and speech pathology (2.34, 1.08-5.10); urban (vs suburban) schools (1.96, 1.39 to 2.77 ); schools with $<50(4.33,1.69$ to 11.06$)$ and $50-100(1.89,1.01$ to 3.54$)$ versus $500-1000$ students; schools with inadequate resources (always/frequently vs sometimes: 1.89, 1.22 to 2.95), inadequate building safety (always and frequently vs sometimes: 6.34, 2.01 to 20.02 and 2.29, 1.14 to 4.61, respectively), soft light versus bright as daylight (1.40, 0.96-2.04) and with physical barriers (1.54, 1.10 to 2.15$)$. Decreased risks were identified for having: routine locker searches $(0.50,0.29$ to 0.86$)$; school sizes $1000+$ versus $500-1000$ students $(0.52,0.33$ to $0.80)$ and easily accessible exits ( $0.33,0.16$ to 0.67$)$; and never (vs sometimes) having inadequate building safety $(0.59,0.37$ 


\section{IP Safety 2010 abstracts}

to 0.94$)$. Results suggest opportunities for targeted interventions and further research to decrease assault risk to educators with benefits to others in school environments. 